\title{
The efficacy of cognitive behavioural therapy for adults with ADHD: A systematic review and meta-analysis of randomised controlled trials
}

\begin{abstract}
Objective: To systematically review published RCTs of cognitive behavioural therapy (CBT) for adult ADHD and establish the effectiveness of CBT reducing ADHD symptoms. Method: A systematic review of nine RCTs and two subsequent meta-analyses of eight of the studies were conducted. Results: Just nine studies were identified, of generally good quality but with some limitations. Four trials (total $N=160$ ) compared CBT to waiting list controls and three trials (total $N=191$ ) compared CBT to appropriate active control groups. Meta-analyses showed that CBT was superior to waiting list with a moderate to large effect size (standardised mean difference [SMD] $=0.76,95 \%$ CI 0.21 to $1.31, p=.006$ ) and superior to active control groups with a small to moderate effect size (SMD $=0.43,95 \%$ CI 0.14 to $0.71, p=.004)$. Conclusion: These results give support to the efficacy of CBT in combination with medication in reducing symptoms of ADHD immediately post-intervention.
\end{abstract}

Keywords: $C B T, A D H D, R C T$, meta-analysis, systematic review

\section{Background}

Attention Deficit Hyperactivity Disorder (ADHD) is a neurodevelopmental condition characterised by three core symptoms: inattention, hyperactivity and impulsivity (American Psychiatric Association $[A P A], 2013$ ) and affects around 4-5\% of the adult population (Kessler et al., 2006). ADHD is increasingly recognised as lifelong for the majority with symptoms persisting into adulthood for two-thirds of people (Wilens, Faraone, \& Biederman, 2004). Commonly it is the hyperactive element that is thought to 
desist, but inattention and impulsivity remain (Advokat, Martino, Hill, \& Gouvier, 2007). There are high rates of psychiatric comorbidity (e.g. depression, substance misuse; 7075\% comorbidity (Wilens, Biederman, \& Spencer, 2002)) and poorer outcomes (e.g. more car accidents, higher divorce rates, and more frequent job changes than adults without ADHD (Faraone et al., 2000; Wilens et al., 2004) especially for those diagnosed in adulthood (Klein et al., 2012).

The first-line treatment for ADHD is pharmacotherapy (National Institute for Health and Care Excellence [NICE], 2013), with most research on adults focussing on medication efficacy (Faraone \& Glatt, 2010; Spencer et al., 2005; Wilens, Spencer, \& Biederman, 2001). Pharmacotherapy has been found to be effective for some; however, $20-50 \%$ of adults are either not suitable for medication, are classed as 'non-responders' or are unable to tolerate the side-effects (Wilens et al., 2001). Even for those for whom medication is effective, symptoms have only been reduced by up to $30 \%$ (Wilens et al., 2001). Less is known about how well medication treats the functional impairment - such as time management and organisation - and arguably it neglects the wider social and emotional relationships, and quality of life difficulties that people experience (Biederman et al., 1993; Faraone et al., 2000; Wilens et al., 2004).

Psychotherapy is much less researched for this population although it is becoming more widely used as an adjunct or alternative to pharmacotherapy, with NICE guidelines now recommending a multimodal approach to treatment (NICE, 2013). Cognitive Behavioural Therapy (CBT) is a group of interventions that comprise a number of basic features, including psychoeducation, cognitive restructuring and skills training, with the aim of changing cognitions and behaviour and ultimately reducing psychological distress. It is important to acknowledge that variation exists between different types of CBT and its application between clinicians, but all share the aforementioned core features and theoretical basis. To date the evidence base for the use of CBT with people with ADHD is scant but arguments for its use are beginning to emerge. 
Based on the premise that ADHD has a neurobiological basis, Safren, Sprich, Chulvick, and Otto (2004) have proposed a CBT model of ADHD, which highlights the importance of functional impairments in ADHD (such as working memory, inhibitory control and sustained attention) underpinning the core symptoms of inattention, hyperactivity and impulsivity. They argue that such impairments hinder learning or adapting coping strategies, resulting in continued difficulties. Adults may have lived with the condition untreated for many years and a potential history of failure or negative experiences may affect cognitions. This may in turn affect motivation, reducing the likelihood of learning better coping. Learning compensatory skills may be intrinsic to reducing functional impairment and $\mathrm{CBT}$, by targeting negative cognitions, may also serve to impact on the emotional aspects of ADHD (Safren et al., 2004).

CBT is gathering evidence as a credible treatment for ADHD with the emergence of reviews of psychological treatments for ADHD (Knouse, Cooper-Vince, Sprich, \& Safren, 2008; Weiss et al., 2008), highlighting a number of uncontrolled CBT studies (Rostain \& Ramsay, 2006; Solanto, Marks, Mitchell, Wasserstein, \& Kofman, 2008; Virta et al., 2008) as showing promising results in terms of ADHD symptom reduction. However, these studies are limited by small samples sizes and lack of control groups and in recent years randomised controlled trials (RCTs) have begun to emerge (e.g. Emilsson et al., 2011; Safren et al., 2010; Stevenson, Whitmont, Bornholt, Livesey, \& Stevenson, 2002). One review (Knouse \& Safren, 2010) estimated effect sizes from a range of controlled studies under the CBT umbrella suggesting moderate to large effects of treatment; however, a pooled effect size is also presented which does not weight the studies by sample size. A further review (Mongia \& Hechtman, 2012) also looked at RCTs from 2004 onwards. However, this review was not systematic, rendering it not replicable and potentially biased. It also included a study that was not an RCT (Bramham et al., 2009). To date there is no published systematically conducted meta-analysis of studies of the 
efficacy of CBT for ADHD. In addition, existing reviews have not systematically assessed the quality of existing studies.

The aim of the review is to investigate the efficacy of CBT for adults with ADHD. The objectives were: 1 ) To systematically identify and assess the quality of RCTs investigating the efficacy of CBT for adults with ADHD; 2) To use meta-analysis to determine whether CBT was better than either waiting list control or an alternative nonCBT control in reducing symptoms of $A D H D ; 3)$ To make recommendations for future practice and research, based on the findings of the review.

\section{Method}

\section{Meta-analysis}

Studies investigating the efficacy of CBT for adult ADHD are limited by small sample sizes; therefore pooling the results of the studies gave the review higher statistical power than any of the single studies. Meta-analysis allows pooling of data with variation in sample sizes accounted for and therefore allows conclusions to be drawn or at least guidance of discussion from the data already available. Pooling results in meta-analyses however, can also accentuate the risk of bias. The results from meta-analyses can also be influenced significantly by the inclusion of poor quality studies, although this is often overlooked by researchers and potentially results in biased reviews (Jüni et al., 2001). Meta-analyses may not always be reliable or valid; in some cases meta-analyses using the same studies have found differing results (Green \& Taplin, 2003). To address such shortcomings in meta-analyses of RCTs specifically, the QUOROM Statement (Quality of Reporting of Meta-Analyses) was developed (Moher et al., 1999) and updated with the PRISMA statement (Preferred Reporting Items for Systematic reviews and MetaAnalyses) (Moher et al., 2009). These guidelines acknowledged the poor quality of reviews with the aim of improving the quality of future reporting. This review therefore presents a meta-analysis of RCTs and pilot RCTs and is guided by the PRISMA statement 
(Moher et al., 2009), to address biases and methodological flaws apparent in many existing reviews.

\section{Criteria for Inclusion of Studies \\ Types of Studies}

RCTs or pilot RCTs reporting a comparison of CBT with an adequate control group were included if they were published in a peer-reviewed journal. Quality of studies was not used as an excluding criteria. The acronym PICO was developed to provide consistency in identifying studies for reviews of clinical research (Stillwell, Fineout-Overholt, Melnyk, \& Williamson, 2010) where: (P) patient population, (I) intervention, (C) comparison group, and (O) outcome. PICO was adopted and exhibited by the following criteria:

\section{Types of Participants}

All studies included participants with ADHD as defined by any diagnostic criteria. Symptom severity, longevity of symptoms, the presence of comorbid psychiatric conditions and gender did not exclude studies from selection. Age was an exclusion criteria with only studies using adult participants (over 18 years) being selected.

\section{Types of Interventions and Comparison Group}

The review only included studies reporting the use of CBT or therapies under the CBT umbrella (such as meta-cognitive therapy which is a group CBT approach) as the experimental condition and a control condition of either wait list (waiting list for CBT treatment) or active (alternative treatment to $\mathrm{CBT}$ ). Although a priori criteria initially defined the control conditions as 'inactive (wait list or treatment as usual)' or 'active' (alternative treatment to CBT), all papers with an inactive control were found to use wait list (rather than 'treatment as usual'). The active control treatment was defined by each study individually, but was some alternative treatment to CBT, such as relaxation (see results for more details). Studies were not excluded based on whether medication was used in either condition. 


\section{Types of Outcome Measures}

Studies that included results from post-treatment continuous outcome measures assessing ADHD symptom severity were included. This allowed for comparison between treatment and control groups to determine response to CBT. Due to variability in types of ADHD symptom scales used across studies, any ADHD rating scale was acceptable if it was based on the DSM diagnostic criteria. Studies should have reported means (standardised or un-standardised) and standard deviations (SD) in order to meet the criteria for meta-analysis. It was hoped that effect sizes for improvement of inattention, hyperactivity, and impulsivity could have been examined separately, but this was not possible as included papers often did not report each subscale independently.

\section{Information Sources and Search Strategy}

A systematic search of the following databases was conducted using an a-priori defined search string: MEDLINE, PsycINFO, CINAHL and EMBASE. The following headings and keywords were used: (a) "cognitive behavioural therapy" OR "CBT" OR "cognitive therapy" OR "cognitive behavio* therap*"; (b) "attention deficit hyperactivity disorder" OR "ADHD" OR "attention deficit disorder"; (C) "randomised controlled trial" OR "RCT" OR "random* control* trial". Searches were limited to studies using adult participants (over 18 years) that were published in the English Language.

\section{Study Selection}

Figure 1 outlines the initial identification of 70 studies and the process through which the final eight studies were selected for inclusion and analysis.

\section{Meta-analysis Procedure}

Two meta-analyses aimed to address the questions of whether CBT was (1) better than waiting list control or (2) better than an alternative non-CBT control in reducing symptoms of ADHD. In studies with active controls, participants would have received 
more clinical contact (regardless of the content of that contact) than those on waiting lists, and there may therefore be distinct results between waiting list and active controls. The meta-analyses were conducted using the software Review Manager 5 (Cochrane, 2008). Two meta-analyses were conducted on eight selected RCTs: five studies compared CBT with waiting list controls (CBT-waitlist) and three studies compared CBT with an active control group (CBT-active). Two RCTs (Pettersson, Söderström, EdlundSöderström, \& Nilsson, 2014; Virta et al., 2010) included each had two treatment groups and one control group. In these cases the active CBT treatment group and inactive waiting list control groups were included in the analysis. Decisions on which ADHD outcome measure to use in the meta-analysis were made on a case-by-case basis depending on the measures used or reported in each study. Where available, independent evaluator assessments were chosen over self-reported measures. When only self-reported measures were employed these were used. However, sensitivity analyses were conducted to ascertain whether pooled results were biased by inclusion of studies that relied on self-report assessment: independent evaluation of post-treatment symptoms would be considered the 'gold standard' and self-report measures could be biased by participants not being blinded to their treatment allocation. Additional sensitivity analyses were undertaken to determine whether pooled results were biased by inclusion of studies appraised as being of lower quality (described further under 'Quality Assessment and Risk of Bias').

It was intended that the meta-analysis would look at outcome measures post-therapy and at follow-up. However, due to an absence of follow-up data within the included studies it was only possible to conduct a meta-analysis on the post-therapy data and not at follow-up points.

Effect sizes of ADHD symptoms were estimated by standardised mean difference (SMD; Hedges' adjusted $g$ ), weighted by sample size using a random effects model in CBTwaitlist (to take both within- and between-study variation into account) and a fixed 
effect model in CBT-active (to take within-study variation into account). The reason for a fixed effects model to analyse the CBT-active control studies was that there were too few (three) studies to use a random effects model, whereas the five studies (CBT-waitlist) could be analysed using the preferred random effects model. A confidence interval of $95 \%$ was used. Effect sizes of $0.2,0.5$, and 0.8 are deemed small, moderate and large respectively (Cohen, 1988).

\section{Heterogeneity}

Tests of heterogeneity should be used in meta-analyses to ascertain whether the trials are similar enough in terms of methodology, participants and interventions employed. Statistical heterogeneity should also be assessed to ensure that trials are suitable to pool the results and this is measured by the $I^{2}$ statistic where $0 \%$ is low heterogeneity and $100 \%$ is high heterogeneity. $I^{2}$ scores of $85 \%$ or higher suggest that a meta-analysis is not appropriate.

\section{Results}

\section{Results of the Review}

\section{Data Extraction and Synthesis}

For each study the following data was extracted: authors; year or publication; location; study aims; sample size and composition; inclusion/exclusion criteria; how participants were diagnosed; concealment of allocation; level of blinding; intention to treat (ITT); participant withdrawal; data collection; measures used and their outcomes; and key findings.

\section{Participants}

The studies included were conducted across seven countries. They had a total of 386 participants, 173 male and 213 female. The overall age range was difficult to establish 
as most studies gave only an average age. Length of time since diagnosis was not given by any studies.

\section{Quality Assessment and Risk of Bias}

In order to assess the reliability of study results, it is necessary to assess the quality and risk of bias in each of the studies included in the analysis. A number of measures has been designed for use in RCTs. However, the use of scales to assess bias is a contentious issue due to a lack of evidence for their accurate assessment of validity and their use of summary scores (Jüni et al., 2001). Some argue against the use of such scales that create summary scores (Higgins et al., 2011; Jüni et al., 2001), in favour of tools designed to guide your assessment of risk of bias; therefore a quality assessment tool based on Brown and colleagues (2013), along with recommendations by Higgins and colleagues (2011), and without the use of summary scores, was used as a guide to structure the assessment of quality. Publication bias was not examined due to there being too few studies to include.

CBT-waitlist: The results of the quality assessment are shown in Table 1. Only one out of the five studies described the method of randomisation and reported having concealed allocation of treatment group. Arguably this is a fundamental feature of RCTs and future research should aim to describe the method in more detail. All five studies reported inclusion and exclusion criteria and information on baseline comparability between the treatment and control groups. It was notable that all studies stipulated that participants on medication should maintain their dose during the study. All reported at least some participants not adhering to this but only four studies reported on how the effects of this were accounted for by way of statistical analysis. No studies were excluded based on their quality assessment; however, a sensitivity analysis was planned as a second stage to the quality assessment, to determine whether pooled meta-analytic results were biased by inclusion of studies with lower quality ratings. Specifically, sensitivity analysis was planned to test whether pooled estimates were robust to inclusion of the CBT- 
waitlist study meeting fewest quality-assessment criteria (Virta et al., 2010). Sensitivity analysis outcomes are reported under 'Results from the Meta-analysis'.

CBT-active: The quality assessment of the studies comparing CBT with an active control group is shown in Table 2. One out of the four studies described the randomisation process; however, no studies reported concealment of allocation to treatment group. All four studies reported baseline characteristics and achieved comparability, reported inclusion criteria and had blinded evaluators. Of the three studies where all participants were on medication, one study described all participants maintaining their dose and two studies reported that some of their participants changed dose during the study; two of these three studies described how they accounted for these medication changes. Only one of the four studies asked their participants to refrain from any other treatments during the study. As described for CBT-waitlist studies, sensitivity analysis was planned to assess the impact of including lower-quality studies; specifically, to test whether pooled estimates were robust to inclusion of the CBT-active study meeting fewest quality-assessment criteria (Weiss et al., 2012). Sensitivity analysis outcomes are reported under 'Results from the Meta-analysis'.

\section{Additional relevant information from studies}

Some studies reported additional information, which may be related to the efficacy of CBT within their trials.

CBT-waitlist: Table 3 shows the five studies comparing CBT with waiting list control groups. CBT was the treatment group in all studies, although some CBT variations were included, namely cognitive remediation and meta-cognitive therapy, due to the similarity in content. The studies used a range of outcome measures. However, the only consistent measure was of ADHD symptom ratings, therefore subsequent analyses focussed only on ADHD symptoms. All five studies found CBT to be superior to waiting list controls (with 
the majority of participants in each group on medication) and the three studies that collected follow-up data found that gains were maintained post treatment from twomonths up to one-year (Emilsson et al., 2011; Pettersson et al., 2014; Stevenson et al., 2002). Improvements in comorbid symptoms of anxiety and depression were found in some studies (Emilsson et al., 2011; Safren et al., 2005) but not others (Stevenson et al., 2002) and improvements were also found in organisation, self-esteem and anger management (Stevenson et al., 2002).

One study (Emilsson et al., 2011) gave additional individual coaching between the group CBT sessions (by psychology undergraduates trained by the group facilitators) with the aim of helping participants to transfer skills learned to their daily lives. Another study (Stevenson et al., 2002) used support people (a minimum of one telephone call between sessions) for participants, to help with appointment reminders, note-taking, and any difficulties encountered during the study. The supporters were either nominated by the participant or were a psychology student, and met with participants between group sessions. Contact time with clinicians and supporters was not controlled for. Two studies also offered additional optional sessions on relaxation and sleep (Pettersson et al., 2014) or memory, impulsivity, anger management or an extra session on topics previously covered (Virta et al., 2010).

CBT-active: The above studies are limited by the treatment group receiving more clinician attention than the control group, so non-specific treatment effects have not been controlled for. Improving on this, Table 4 shows four studies comparing CBT with an active control group, for example relaxation with educational support, supportive therapy and psychoeducation or placebo medication. Three out of the four studies used independent evaluators post-treatment and only two collected follow-up data; therefore only immediately post-intervention outcomes were analysed. 
One study (Estrada et al., 2013) delivered one of the CBT sessions with a family member of each group participant present. Another (Safren et al., 2010) offered additional optional sessions on either procrastinating, a session with a family member or booster sessions on topics already covered. The only study that investigated comorbid symptoms of anxiety and depression found no significant improvements (Solanto et al., 2010).

The above studies employed a range of group and individual control treatments and found mixed results; two studies found $C B T$ to be superior to relaxation with educational support (Safren et al., 2010) and supportive psychotherapy (Solanto et al., 2010) and one study found a negative effect so that psychoeducation was more effective than CBT (although not significantly) (Estrada et al., 2013). Follow-up data were only collected by one study where treatments gains were maintained up to nine months post-treatment (Safren et al., 2010).

\section{Results from the Meta-analysis}

CBT-waitlist: Table 5 shows summary statistics for the range of ADHD symptom scales scores comparing post-intervention ADHD symptom measures between treatment and control groups showing that people receiving CBT were more likely to see reduced symptom severity than those in the waiting list control group $(n=5 ;$ SMD $=0.76 ; 95 \%$ CI 0.21 to $1.31, p=.006$; random effects model). The plot in Figure 2 shows an advantage for treatment over control with all studies' point estimates and the diamond showing the pooled effect appearing to the left of the axis. Chi square test of heterogeneity looks for whether the differences between the studies' results could be due to chance. $I^{2}$ values between 40 and $84 \%$ call for a random effect method due to high heterogeneity. Heterogeneity was calculated as $I^{2}=63 \%$ suggesting moderate heterogeneity. Effect sizes (SMDs; Hedges' adjusted $g$ ) for each individual study are also reported in Figure 2 and range between 0.20 and 1.75, suggesting small to large effect sizes. 
Sensitivity analysis was conducted to ascertain whether pooled estimates were robust to the inclusion of studies that only employed self-report measures. The advantage for treatment over control remained after removal of two studies that relied on self-report (Pettersson et al., 2014; Stevenson et al., 2002): $\mathrm{n}=3$; SMD $=0.65 ; 95 \% \mathrm{CI} 0.20$ to $1.09 ; p=.004$. Among the remaining studies, heterogeneity reduced to $I^{2}=2 \%$. A second sensitivity analysis was conducted to test for robustness to the inclusion of studies with lower methodological quality (as assessed against applied criteria; Table 1). The advantage for treatment over control remained after removal of the lowest quality study (Virta et al., 2010): $\mathrm{n}=4$; SMD $=0.88 ; 95 \%$ CI 0.53 to $1.24 ; p<.001 ; I^{2}=$ $66 \%$.

CBT-active: After the exclusion of one study for employing CBT in both treatment conditions (Weiss et al., 2012), three studies remained eligible for meta-analysis. Table 5 shows summary statistics for the range of ADHD symptom scales scores comparing post-intervention ADHD symptom scores between CBT treatment and active control groups showing that people receiving CBT were more likely to see reduced symptom severity than those in the active control group $(n=3 ;$ SMD $=0.43 ; 95 \%$ CI 0.14 to $0.71, p=.004 ;$ fixed effects model). The plot in Figure 3 shows an advantage for treatment over control with two out of three studies' point estimates, and the diamond showing the pooled effect, appearing to the right of the axis. Heterogeneity was calculated as $I^{2}=31 \%$ suggesting low heterogeneity. Effect sizes for the individual studies are also reported in Table 5, ranging between -0.13 and 0.57 , suggesting a range between a negative effect and medium effect.

Sensitivity analysis was conducted to ascertain whether pooled estimates were robust to the inclusion of studies that only employed self-report measures. The advantage for treatment over control remained after removal of one study that relied on self-report (Estrada et al., 2013): $\mathrm{n}=2 ; \mathrm{SMD}=0.54 ; 95 \%$ CI 0.22 to $0.86 ; p<.001 ; I^{2}=0 \%$. 
The CBT-active study with the lowest quality rating (Weiss et al., 2012) was excluded from the pooled estimate reported above; consequently, the second planned sensitivity analysis - to test for robustness of results to inclusion of the lowest quality study - was not conducted.

\section{Discussion}

Nine RCTs examining the effect of CBT on ADHD symptoms in adults were identified in the review, with eight of these studies being eligible for the meta-analyses. Two metaanalyses were conducted due to differences in control groups; CBT-waitlist compared CBT with waiting list controls and CBT-active compared CBT with an appropriate, active control group. Methodological differences between studies prevented further analyses of measures such as quality of life, comorbidities and maintenance of treatment gains at follow-up. Results from the meta-analyses show a benefit of CBT over waiting list controls and active controls in the reduction of ADHD symptoms immediately posttreatment. A number of recommendations for future research and clinical practice can be drawn from the review.

The study quality assessment highlighted that the studies were generally of good quality with most of the quality criteria met or partially met. Significantly, a number of studies did not show that they were truly random. This may have biased their results and, in turn, the findings of the current review, although sensitivity analyses showed that the results of the meta-analyses were robust to the removal of lower quality studies. Due to the nature of treatment vs. control groups, blinding of those giving treatment and participants is not possible, which may be a further limitation. With the exception of one study (Estrada et al., 2013) which found a negative effect, all the studies showed a positive effect of CBT over the control condition. However, to what extent this effect is 
influenced by publication bias is unclear as negative results are less likely to have been published.

The results from the $C B T$-waitlist meta-analysis were limited by studies using an inactive control group, reducing the experimental rigour (MacCoon et al., 2012). Some argue that shared effects of therapy need to be controlled for in psychological therapy research (Jensen, Weersing, Hoagwood, \& Goldman, 2005) but others argue that the methodologies of pharmaceutical trials should not be translated to psychological therapies as shared effects are part of therapy and should not be controlled for (Bentall, 2009). Several studies did not employ independently assessed post-treatment measures, which could impact on the results, as self-reported measures are limited by participants not being blinded as to whether they received the intervention, further highlighting the need for active control groups. The CBT-active analyses went some way in improving these limitations by employing active control conditions such as psychoeducation or supportive therapy groups. These results can counteract the argument that the group environment or amount of attention given to those receiving the active treatment intervention is the reason for treatment effects. However, only a small number of studies were available for this analysis, one of which did not use independent assessors of posttreatment outcomes.

The majority of participants included in the review were taking ADHD medication during the trial. Although many studies requested that those on medication remained on a stable dose, not all participants adhered to this and not all studies monitored this. However, those that had a combination of people on and off medication (Stevenson et al., 2002; Virta et al., 2010) did ensure that there were no between-group differences at baseline. Some studies did not ask their participants to refrain from concurrent psychological treatment and did not collect data on this (e.g. Virta et al., 2010); therefore treatment effects may not be attributable to CBT in such cases. Most studies reported only the overall ADHD symptom score rather than subscales of attention, 
hyperactivity and impulsivity, potentially masking the effects of CBT on each individual core symptom and preventing further subscale analyses. Researcher or therapist allegiance was not discussed in any study, which can be a significant source of bias within studies (Jüni et al., 2001), although in most cases where independent evaluators were utilised, they were blinded to treatment condition reducing the likelihood of bias.

A more thorough meta-analysis of outcomes other than ADHD symptoms was not possible due to insufficient or inconsistent outcome data across studies on measures such as quality of life, with only three of the included studies collecting this data across both analyses (Estrada et al., 2013; Pettersson et al., 2014; Virta et al., 2010) and the measures utilised being too dissimilar. Although some studies collected data on outcomes of comorbidities such as anxiety and depression (Emilsson et al., 2011; Estrada et al., 2013; Pettersson et al., 2014; Safren et al., 2005; Solanto et al., 2010; Virta et al., 2010) and some found significant reductions in symptoms (Emilsson et al., 2011; Safren et al., 2005), there was not sufficient data or sufficient similarities between measures employed for this to be analysed further. As inattention could be a symptom of depression and / or anxiety, it may be useful to conduct more detailed research into the relationship between ADHD symptoms and comorbid anxiety and depression where either are a target of CBT interventions. An analysis of follow-up data was not possible either due to a lack of data, with only a few studies collecting adequate data (Emilsson et al., 2011; Pettersson et al., 2014; Safren et al., 2010) or for not collecting data on both treatment and control groups (Stevenson et al., 2002).

There was insufficient data on functional impairments to evaluate this by meta-analyses, making it difficult to comment on the theory by Safren et al. (2004) that the core symptoms of inattention, hyperactivity and impulsivity are underpinned by functional impairments in ADHD (such as working memory, inhibitory control and sustained attention). The reduction in symptoms seen in the reviewed studies arguably lends support for the theory, although whether this is via learning compensatory strategies, by 
targeting negative cognitions or by other means is unclear. Various authors have speculated that differing aspects of CBT are intrinsic to symptom reduction, for example, discouraging avoidance and procrastination (Bramham et al., 2009), employing cognitive strategies to improve self-esteem through identifying, challenging and replacing negative thoughts (Stevenson et al., 2002), behavioural skills training to develop effective coping strategies (Rostain \& Ramsay, 2006) and understanding the neurobiological basis of ADHD aiding restoration of self-esteem (Safren et al., 2004). However, as yet it is unclear whether a particular aspect of CBT is paramount or whether it is the broad range of cognitions, emotions and behaviours that CBT targets that makes it effective.

Conclusions regarding this cannot be drawn from the current review as detailed analysis of the CBT components and their individual outcomes was not researched in any study.

Despite the limitations of the extant literature, this review adds to the growing evidencebase for the effectiveness of CBT in reducing the symptoms of ADHD and gives rise to recommendations for future research, both in terms of design and questions to be addressed. To improve the rigour of future research, it is recommended that studies use and clearly report true randomisation, with active control groups and discussion of researcher and / or therapist allegiance. Ideally, independently assessed post-treatment measures would be employed, both after treatment and at follow-up points to establish the sustainability of any treatment effects. More attention should be paid to the role of medication and / or other psychological treatments utilised by study participants, for example either by asking participants to refrain or by reporting data on additional treatments to improve the reliability of attributing change to active CBT interventions. Studies measuring ADHD symptoms may benefit from measuring and reporting subscales of attention, hyperactivity and impulsivity to determine which, if any, are most improved as a result of CBT. Additional measures of functional impairments and outcomes such as quality of life and comorbid mental health difficulties may also be helpful. 
Future research could aim to address a number of specific questions to contribute to the evidence base for CBT for ADHD. These include whether group or individual therapy is most useful, what the optimal length and number of sessions is and what time period of treatment is most efficacious. More detailed research into the efficacy of the various components of CBT will help us to understand the process by which CBT helps to reduce ADHD symptoms. Further research is also needed to build on the results from Weiss et al. (2012) suggesting that medication did not provide any additional benefit to CBT, an important implication for those who choose not to take medication, or for those whom medication is ineffective or intolerable. Ideally, for conclusions to be drawn, future studies would employ three conditions: CBT; active control group; TAU. Future reviews should also seek to synthesise data from CBT groups compared with other active therapeutic approaches unrelated to CBT in order to determine whether CBT is superior to other therapies. 


\section{References}

Advokat, C., Martino, L., Hill, B., \& Gouvier, W. (2007). Continuous Performance Test (CPT) of college students with ADHD, psychiatric disorders, cognitive deficits, or no diagnosis. Journal of Attention Disorders, 10(3), 253-256.

Bentall, R. P. (2009). Doctoring the mind: Why psychiatric treatments fail: Penguin UK. Biederman, J., Faraone, S. V., Spencer, T., Wilens, T., Norman, D., Lapey, K. A., . . . Doyle, A. (1993). Patterns of psychiatric comorbidity, cognition, and psychosocial functioning in adults with attention deficit hyperactivity disorder. The American Journal of Psychiatry(150 (12)), 1792-1798.

Bramham, J., Susan, Y., Bickerdike, A., Spain, D., McCartan, D., \& Xenitidis, K. (2009). Evaluation of group cognitive behavioral therapy for adults with ADHD. Journal of Attention Disorders, 12(5), 434-441. doi:10.1177/1087054708314596

Brown, T., Pilkington, G., Bagust, A., Boland, A., Oyee, J., Smith, C. T., . . . Greenhalgh, J. (2013). Clinical effectiveness and cost-effectiveness of first-line chemotherapy for adult patients with locally advanced or metastatic non-small cell lung cancer: a systematic review and economic evaluation. NIHR Journals Library, 17.31. doi: $10.3310 /$ hta 17310

Cohen, J. (1988). Statistical power analysis for the behavioral sciences (2nd ed.). Hillsdale, NJ: Lawrence Erlbaum.

Emilsson, B., Gudjonsson, G., Sigurdsson, J. F., Baldursson, G., Einarsson, E., Olafsdottir, H., \& Young, S. (2011). Cognitive behaviour therapy in medicationtreated adults with ADHD and persistent symptoms: A randomized controlled trial. BMC Psychiatry, 11, 116. doi:http://dx.doi.org/10.1186/1471-244X-11-116

Estrada, R. V., Bosch, R., Nogueira, M., Gomez-Barros, N., Valero, S., Palomar, G., . . . Ramos-Quiroga, J. A. (2013). Psychoeducation for adults with attention deficit hyperactivity disorder vs. cognitive behavioral group therapy: a randomized controlled pilot study. Journal of Nervous \& Mental Disease, 201(10), 894-900. doi:http://dx.doi.org/10.1097/NMD.0b013e3182a5c2c5

Faraone, S. V., Biederman, J., Spencer, T., Wilens, T., Seidman, L. J., Mick, E., \& Doyle, A. E. (2000). Attention-deficit/hyperactivity disorder in adults: an overview. Biological Psychiatry, 48(1), 9-20.

Faraone, S. V., \& Glatt, S. J. (2010). A comparison of the efficacy of medications for adult attention-deficit/hyperactivity disorder using meta-analysis of effect sizes. The Journal of clinical psychiatry, 71(6), 754-763.

Green, B. B., \& Taplin, S. H. (2003). Breast cancer screening controversies. The Journal of the American Board of Family Practice, 16(3), 233-241. 
Higgins, J. P., Altman, D. G., Gøtzsche, P. C., Jüni, P., Moher, D., Oxman, A. D., . . Sterne, J. A. (2011). The Cochrane Collaboration's tool for assessing risk of bias in randomised trials. $B m j, 343$, d5928.

Jensen, P. S., Weersing, R., Hoagwood, K. E., \& Goldman, E. (2005). What is the evidence for evidence-based treatments? A hard look at our soft underbelly. Mental health services research, 7(1), 53-74.

Jüni, P., Altman, D. G., \& Egger, M. (2001). Assessing the quality of controlled clinical trials. Bmj, 323(7303), 42-46. doi:10.1136/bmj.323.7303.42

Kessler, R. C., Adler, L., Barkley, R., Biederman, J., Conners, C. K., Demler, O., . . . Secnik, K. (2006). The prevalence and correlates of adult ADHD in the United States: results from the National Comorbidity Survey Replication. The American Journal of Psychiatry, 163(4), 716-723.

Klein, R. G., Mannuzza, S., Olazagasti, M. A. R., Roizen, E., Hutchison, J. A., Lashua, E. C., \& Castellanos, F. X. (2012). Clinical and functional outcome of childhood attention-deficit/hyperactivity disorder 33 years later. Archives of general psychiatry, 69(12), 1295-1303.

Knouse, L. E., Cooper-Vince, C., Sprich, S., \& Safren, S. A. (2008). Recent developments in the psychosocial treatment of adult ADHD. Expert Review of Neurotherapeutics, 8(10), 1537-1548. doi:http://dx.doi.org/10.1586/14737175.8.10.1537

Knouse, L. E., \& Safren, S. A. (2010). Current status of cognitive behavioral therapy for adult attention-deficit hyperactivity disorder. Psychiatric Clinics of North America, 33(3), 497-509. doi: http://dx.doi.org/10.1016/j.psc.2010.04.001

MacCoon, D. G., Imel, Z. E., Rosenkranz, M. A., Sheftel, J. G., Weng, H. Y., Sullivan, J. C., . . . Lutz, A. (2012). The validation of an active control intervention for Mindfulness Based Stress Reduction (MBSR). Behaviour Research and Therapy, 50(1), 3-12. doi: http://dx.doi.org/10.1016/j.brat.2011.10.011

Moher, D., Cook, D. J., Eastwood, S., Olkin, I., Rennie, D., Stroup, D. F., \& Group, Q. (1999). Improving the quality of reports of meta-analyses of randomised controlled trials: the QUOROM statement. The Lancet, 354(9193), 1896-1900.

Moher, D., Liberati, A., Tetzlaff, J., \& Altman, D. G. (2009). Preferred reporting items for systematic reviews and meta-analyses: the PRISMA statement. Annals of internal medicine, 151(4), 264-269.

Mongia, M., \& Hechtman, L. (2012). Cognitive behavior therapy for adults with attentiondeficit/hyperactivity disorder: a review of recent randomized controlled trials. Current Psychiatry Reports, 14(5), 561-567. doi:http://dx.doi.org/10.1007/s11920-012-0303-x

Pettersson, R., Söderström, S., Edlund-Söderström, K., \& Nilsson, K. W. (2014). Internet-Based Cognitive Behavioral Therapy for Adults With ADHD in Outpatient Psychiatric Care A Randomized Trial. Journal of Attention Disorders, 1087054714539998.

Rostain, A. L., \& Ramsay, J. R. (2006). A combined treatment approach for adults with ADHD - Results of an open study of 43 patients. Journal of Attention Disorders, 10(2), 150-159. Retrieved from http://gateway. ovid.com/ovidweb.cgi?T=JS\&CSC $=Y \& N E W S=N \& P A G E=$ fulltext\&D =emed7\&AN $=17085625$

http://sfx.nottingham.ac.uk:80/sfx local?genre=article\&atitle $=A+$ combined + treatment + approach+for+adults+with+ADHD+-

+ Results+of+an+open+study+of $+43+$ patients\&title=Journal+of+Attention+Diso rders\&issn $=1087-$

$0547 \&$ date $=2006 \&$ volume $=10$ \&issue $=2 \&$ spage $=150 \&$ aulast $=$ Rostain + A. L. \&isbn $=$ \& char set $=$ utf8

Safren, S. A., Otto, M. W., Sprich, S., Winett, C. L., Wilens, T. E., \& Biederman, J. (2005). Cognitive-behavioral therapy for ADHD in medication-treated adults with continued symptoms. Behaviour Research \& Therapy, 43(7), 831-842. Retrieved from 
http://gateway.ovid.com/ovidweb.cgi?T=JS\&CSC $=Y \& N E W S=N \& P A G E=$ fulltext\&D $=$ med5\&AN $=15896281$

http://sfx.nottingham.ac.uk:80/sfx local?genre=article\&atitle=Cognitive-

behavioral+therapy+for+ADHD+in+medication-

treated+adults+with+continued+symptoms.\&title=Behaviour+Research $+\% 26+T$

herapy\&issn $=0005-$

7967\&date $=2005 \&$ volume $=43 \&$ issue $=7 \&$ spage $=831$ \&aulast $=$ Safren + SA\&isbn $=\&$ char set $=$ utf8

Safren, S. A., Sprich, S., Chulvick, S., \& Otto, M. W. (2004). Psychosocial treatments for adults with attention-deficit/hyperactivity disorder. Psychiatric Clinics of North America, 27(2), 349-360. Retrieved from

http://gateway. ovid.com/ovidweb.cgi?T=JS\&CSC $=Y \& N E W S=N \& P A G E=$ fulltext\&D $=$ med5\&AN $=15064001$

http://sfx.nottingham.ac.uk:80/sfx local?genre=article\&atitle=Psychosocial+treatments + for+adults + with+attention-

deficit\%2Fhyperactivity+disorder.\&title=Psychiatric+Clinics + of +North+America\&i $\underline{\mathrm{ssn}=0193-}$

$\underline{953 X \& d a t e}=2004 \&$ volume $=27 \&$ issue $=2 \&$ spage $=349 \&$ aulast $=$ Safren + SA\&isbn $=\&$ char set $=$ utf8

Safren, S. A., Sprich, S., Mimiaga, M. J., Surman, C., Knouse, L., Groves, M., \& Otto, M. W. (2010). Cognitive behavioral therapy vs relaxation with educational support for medication-treated adults with ADHD and persistent symptoms: a randomized controlled trial. JAMA, 304(8), 875-880.

doi:http://dx.doi.org/10.1001/jama.2010.1192

Solanto, M. V., Marks, D. J., Mitchell, K. J., Wasserstein, J., \& Kofman, M. D. (2008). Development of a new psychosocial treatment for adult ADHD. Journal of Attention Disorders, 11(6), 728-736. Retrieved from

http://gateway. ovid.com/ovidweb.cgi?T=JS\&CSC $=$ Y\&NEWS $=$ N\&PAGE=fulltext\&D $=$ med5\&AN $=17712167$

http://sfx.nottingham.ac.uk:80/sfx local?genre $=$ article\&atitle=Development + of $+a+$ new + psychosocial+treatment+for+adult+ADHD.\&title=Journal+of+Attention+Disord ers\&issn $=1087-$

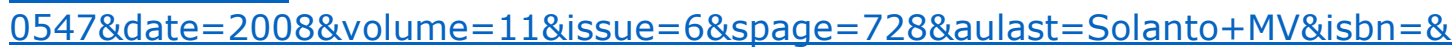
char set $=$ utf8

Solanto, M. V., Marks, D. J., Wasserstein, J., Mitchell, K., Abikoff, H., Alvir, J. M., \& Kofman, M. D. (2010). Efficacy of meta-cognitive therapy for adult ADHD. American Journal of Psychiatry, 167(8), 958-968. doi:http://dx.doi.org/10.1176/appi.ajp.2009.09081123

Spencer, T., Biederman, J., Wilens, T., Doyle, R., Surman, C., Prince, J., . . . Faraone, S. (2005). A large, double-blind, randomized clinical trial of methylphenidate in the treatment of adults with attention-deficit/hyperactivity disorder. Biological Psychiatry, 57(5), 456-463.

Stevenson, C. S., Whitmont, S., Bornholt, L., Livesey, D., \& Stevenson, R. J. (2002). A cognitive remediation programme for adults with Attention Deficit Hyperactivity Disorder. Australian \& New Zealand Journal of Psychiatry, 36(5), 610-616.

Retrieved from

http://gateway.ovid.com/ovidweb.cgi?T=JS\&CSC $=Y \& N E W S=N \& P A G E=$ fulltext\&D $=$ med4\&AN $=12225443$

http://sfx.nottingham.ac.uk:80/sfx local?genre=article\&atitle $=A+$ cognitive+remediation +programme+for+adults+with+Attention+Deficit+Hyperactivity+Disorder.\&title $=$ Australian+\%26+New+Zealand+Journal+of+Psychiatry\&issn $=0004-$

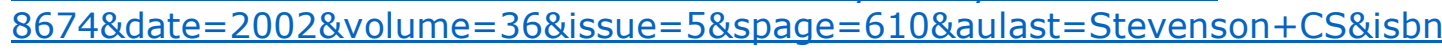
$=\&$ char set $=$ utf8

Stillwell, S. B., Fineout-Overholt, E., Melnyk, B. M., \& Williamson, K. M. (2010). Evidence-based practice, step by step: asking the clinical question: a key step in evidence-based practice. AJN The American Journal of Nursing, 110(3), 58-61. 
Virta, M., Salakari, A., Antila, M., Chydenius, E., Partinen, M., Kaski, M., ... Iivanainen, M. (2010). Short cognitive behavioral therapy and cognitive training for adults with ADHD-A randomized controlled pilot study. Neuropsychiatric Disease and Treatment Vol 6(1), Jul 2010, ArtID 443-453, 6(1). Retrieved from http://gateway.ovid.com/ovidweb.cgi?T=JS\&CSC $=Y \& N E W S=N \& P A G E=$ fulltext\&D =psyc7\&AN $=2013-07175-001$

http://sfx.nottingham.ac.uk:80/sfx local?genre=article\&atitle=Short+cognitive+behavio ral+therapy+and+cognitive+training +for+adults + with+ADHD-

$\underline{A}+$ randomized + controlled + pilot + study.$\&$ title $=$ Neuropsychiatric + Disease + and $+\mathrm{Tr}$ eatment\&issn $=1176-$

6328\&date $=2010 \&$ volume $=6 \&$ issue $=1 \&$ spage $=443 \&$ aulast $=$ Virta $\% 2 C+$ Maarit $\& i s b$ $\underline{\mathrm{n}=\& \text { char set }=\text { utf8 }}$

Virta, M., Vedenpaa, A., Gronroos, N., Chydenius, E., Partinen, M., Vataja, R., . . . Iivanainen, M. (2008). Adults with ADHD benefit from cognitive-behaviorally oriented group rehabilitation: a study of 29 participants. Journal of Attention Disorders, 12(3), 218-226. doi:http://dx.doi.org/10.1177/1087054707311657

Weiss, M., Murray, C., Wasdell, M., Greenfield, B., Giles, L., \& Hechtman, L. (2012). A randomized controlled trial of CBT therapy for adults with ADHD with and without medication. BMC Psychiatry, 12, 30. doi:http://dx.doi.org/10.1186/1471-244X$12-30$

Weiss, M., Safren, S. A., Solanto, M. V., Hechtman, L., Rostain, A. L., Ramsay, J., \& Murray, C. (2008). Research forum on psychological treatment of adults with ADHD. Journal of Attention Disorders, 11(6), 642-651. Retrieved from http://gateway.ovid.com/ovidweb.cgi? T =JS\&CSC $=$ Y\&NEWS $=$ N\&PAGE $=$ fulltext\&D =psyc6\&AN $=2008-05733-005$

http://sfx.nottingham.ac.uk:80/sfx local?genre=article\&atitle=Research + forum + on + psy chological+treatment+of+adults+with+ADHD.\&title=Journal+of+Attention+Disor ders\&issn $=1087-$

0547\&date $=2008 \&$ volume $=11 \&$ issue $=6 \&$ spage $=642 \&$ aulast $=$ Weiss $\% 2 \mathrm{C}+$ Margare t\&isbn $=\&$ char set $=u t f 8$

Wilens, T. E., Biederman, J., \& Spencer, T. J. (2002). Attention deficit/hyperactivity disorder across the lifespan. Annual review of medicine, 53(1), 113-131.

Wilens, T. E., Faraone, S. V., \& Biederman, J. (2004). Attention-deficit/hyperactivity disorder in adults. JAMA: the journal of the American Medical Association, 292(5), 619-623.

Wilens, T. E., Spencer, T. J., \& Biederman, J. (2001). A review of the pharmacotherapy of adults with Attention-Deficit/ Hyperactivity Disorder. Journal of Attention Disorders, 5(4), 189-202. doi:10.1177/108705470100500401 
Page $\mathbf{2 3}$ of $\mathbf{3 1}$ 
Figure 1: Flow chart for identifying relevant studies

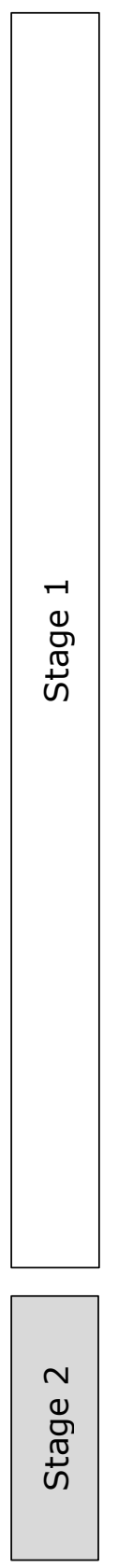

70 studies identified through database searching

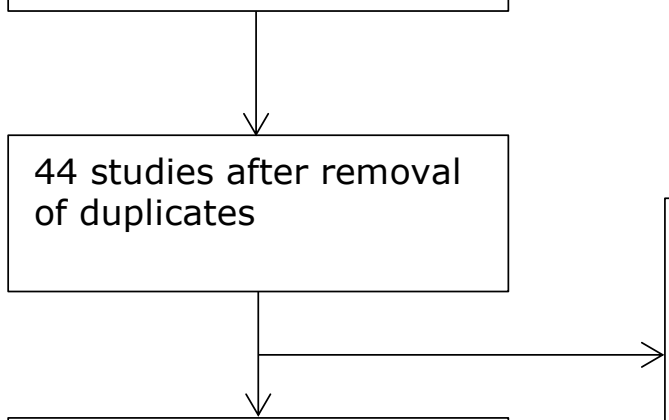

12 full-text articles assessed for eligibility and reference sections

32 studies excluded through abstract screening:

Not ADHD $=10$

Not adults $=11$

Not $\mathrm{CBT}=9$

Not RCT $=2$ trawled

5 studies excluded through full-text screening: $\mathrm{MBCT}=1$ $\mathrm{DBT}=2$

9 studies included in review

Not RCT $=2$

8 studies included in meta-analysis:

CBT vs waiting list $=5^{*}$

CBT vs active control $=4 *$

1 study excluded from

meta-analysis:

CBT as active control $=1$

*Note: one study was used in both meta-analyses 
Table 1: Quality assessment table for studies comparing CBT \pm medication with waiting list \pm medication (CBT-waitlist)

\begin{tabular}{|c|c|c|c|c|c|c|c|c|c|c|c|c|c|c|c|c|c|}
\hline $\begin{array}{l}\text { First } \\
\text { author, } \\
\text { year }\end{array}$ & 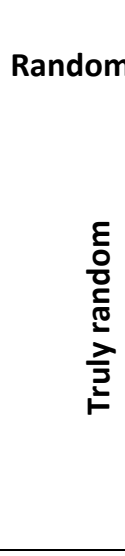 & 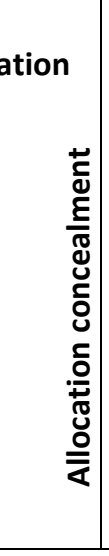 & $\begin{array}{r}\text { Basel } \\
\text { compar }\end{array}$ & 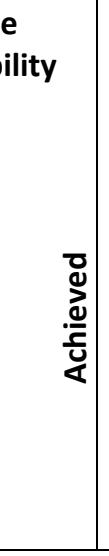 & 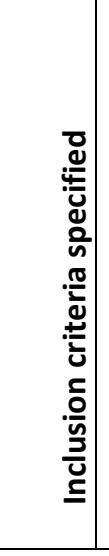 & 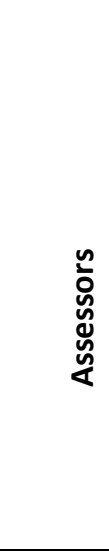 & 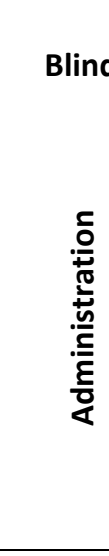 & 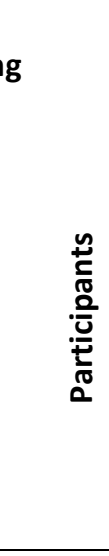 & 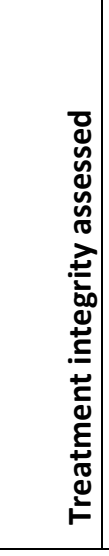 & 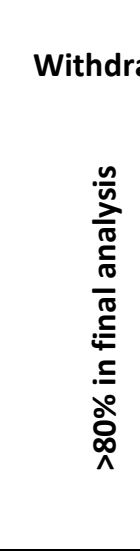 & 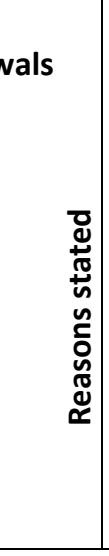 & 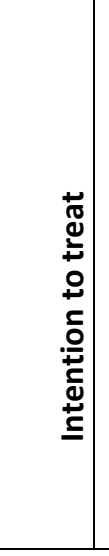 & 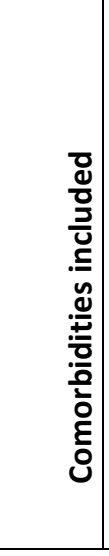 & 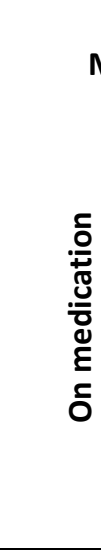 & 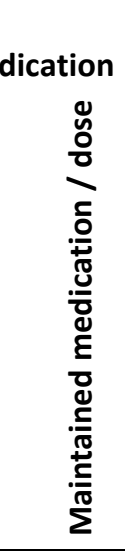 & 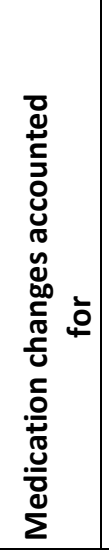 & 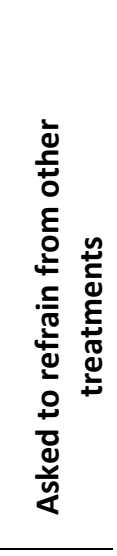 \\
\hline $\begin{array}{l}\text { Emilsson, } \\
2011\end{array}$ & NS & NS & $Y$ & $\mathrm{Y}$ & $Y$ & $Y$ & NS & NA & $\mathrm{Y}$ & $\begin{array}{c}N \\
(74 \%)\end{array}$ & $\mathrm{Y}$ & $Y$ & $\mathrm{Y}$ & $\mathrm{Y}$ & YN & $\mathrm{Y}$ & $\mathrm{N}$ \\
\hline $\begin{array}{l}\text { Pettersson, } \\
2014\end{array}$ & $Y$ & $\mathrm{Y}$ & $Y$ & $Y$ & $Y$ & $Y$ & NS & NA & NS & $\begin{array}{c}N \\
(50 \%)\end{array}$ & $\mathrm{N}$ & $Y$ & YN & $\mathrm{Y}$ & YN & $\mathrm{Y}$ & NS \\
\hline $\begin{array}{l}\text { Safren, } \\
2005\end{array}$ & NS & NS & $Y$ & $\mathrm{Y}$ & $Y$ & $Y$ & NS & NA & NS & $Y$ & NA & $Y$ & YN & $\mathrm{Y}$ & YN & $\mathrm{Y}$ & NS \\
\hline $\begin{array}{l}\text { Stevenson, } \\
2002\end{array}$ & NS & NS & $Y$ & $\mathrm{Y}$ & $Y$ & NS & NS & NA & NS & $Y$ & $\mathrm{Y}$ & $Y$ & $\mathrm{Y}$ & YN & YN & $Y$ & NS \\
\hline $\begin{array}{l}\text { Virta, } \\
2010\end{array}$ & NS & NS & $Y$ & $Y$ & $Y$ & $\mathrm{Y}$ & NS & NA & NS & $Y$ & $\mathrm{~N}$ & $Y$ & YN & YN & YN & NS & Y \\
\hline
\end{tabular}

$\mathrm{Y}=$ yes (item adequately addressed); $\mathrm{N}=$ no (item not adequately addressed); $\mathrm{YN}=$ partially (item partially addressed); $\mathrm{NS}=$ not stated; $\mathrm{NA}=$ not applicable 
Table 2: Quality assessment table for studies comparing CBT \pm medication with active control \pm medication (CBT-active)

\begin{tabular}{|c|c|c|c|c|c|c|c|c|c|c|c|c|c|c|c|c|c|}
\hline Author (year) & Rand & 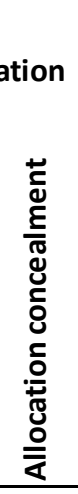 & 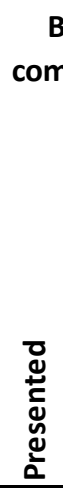 & 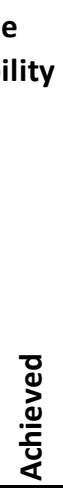 & 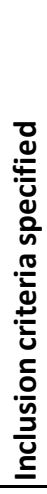 & 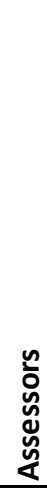 & 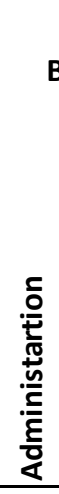 & 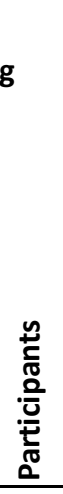 & 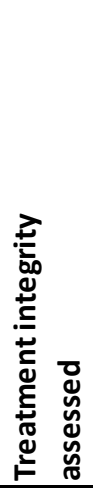 & 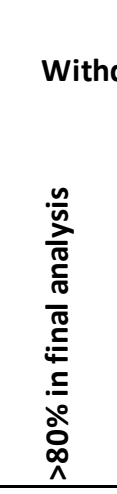 & 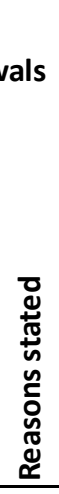 & 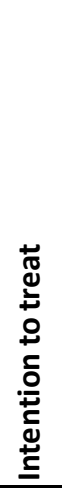 & 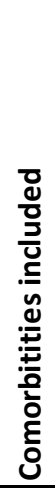 & 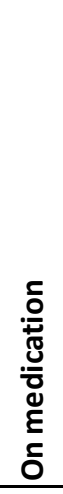 & 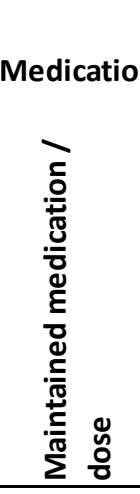 & 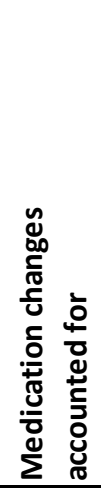 & 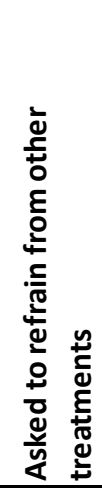 \\
\hline Estrada et al (2013) & Y & NS & Y & $\mathrm{Y}$ & $\mathrm{Y}$ & $\mathrm{Y}$ & NS & NS & Y & Y & $\mathrm{Y}$ & NS & YN & $\mathrm{Y}$ & Y & NA & NS \\
\hline Safren et al (2010) & Y & NS & $\mathrm{Y}$ & $\mathrm{Y}$ & $\mathrm{Y}$ & $\mathrm{Y}$ & NS & $\mathrm{N}$ & $\mathrm{Y}$ & $Y$ & $\mathrm{~N}$ & $\mathrm{Y}$ & $\mathrm{N}$ & $\mathrm{Y}$ & YN & $Y$ & NS \\
\hline Solanto et al (2010) & NS & NS & Y & $\mathrm{Y}$ & $\mathrm{Y}$ & $\mathrm{Y}$ & NS & NS & $Y$ & $N(73 \%)$ & $\mathrm{N}$ & NS & $\mathrm{YN}$ & $\mathrm{Y}$ & YN & $Y$ & $\mathrm{Y}$ \\
\hline Weiss et al (2012) & Y & NS & Y & $\mathrm{Y}$ & $Y$ & $\mathrm{Y}$ & NS & $\mathrm{Y}$ & YN & $\mathrm{N}(70 \%)$ & $\mathrm{N}$ & $\mathrm{Y}$ & $\mathrm{YN}$ & NA & NS & NS & NS \\
\hline
\end{tabular}

$\mathrm{Y}=$ yes (item adequaltely addressed); $\mathrm{N}=$ no (item not adequately addressed); $\mathrm{YN}=$ partially (item partially addressed); $N S=$ not stated; $N A=$ not applicable 
Table 3: Study characteristics table for studies comparing CBT \pm medication with waiting list \pm medication (CBT-wait)

\begin{tabular}{|c|c|c|c|c|c|c|c|c|}
\hline \multirow{2}{*}{$\begin{array}{l}\text { First author, } \\
\text { year, } \\
\text { location }\end{array}$} & \multirow[b]{2}{*}{ Design } & \multirow[b]{2}{*}{ Participants } & \multirow[b]{2}{*}{ CBT arm } & \multirow[b]{2}{*}{ Control arm } & \multirow[b]{2}{*}{ CBT content } & \multicolumn{3}{|c|}{ Assessment } \\
\hline & & & & & & Measure & Assessor & Follow-up? \\
\hline $\begin{array}{l}\text { Emilsson, } \\
2011, \\
\text { Iceland }\end{array}$ & RCT & $\begin{array}{l}\mathrm{N}=54 \\
\mathrm{M}(\mathrm{SD}) \text { age }= \\
33.88(11.47) \\
68 \% \text { female }\end{array}$ & $\begin{array}{l}\text { Group CBT }+ \\
\text { medication }(n=27) \\
15 \text { twice weekly } \\
\text { sessions of } 90 \\
\text { minutes* }\end{array}$ & $\begin{array}{l}\text { Waitlist + } \\
\text { medication }(n=27)\end{array}$ & $\begin{array}{l}\text { Neurocognitive (attention, } \\
\text { memory, impulse control and } \\
\text { planning), problem solving, } \\
\text { emotional control, pro-social skills, } \\
\text { critical reasoning }\end{array}$ & K-SADS & Independent & Yes \\
\hline $\begin{array}{l}\text { Pettersson, } \\
2014, \\
\text { Sweden }\end{array}$ & $\mathrm{RCT}$ & $\begin{array}{l}N=32 \\
M(S D) \text { age }= \\
36.34() \\
69 \% \text { female }\end{array}$ & $\begin{array}{l}\text { Group therapist-led } \\
\text { internet CBT (iCBT) } \pm \\
\text { medication }(n=14) \\
10 \text { weekly sessions of } \\
3 \text { hours }\end{array}$ & $\begin{array}{l}\text { Waitlist } \pm \\
\text { medication }(n=18)\end{array}$ & $\begin{array}{l}\text { Behaviour analysis, mindfulness \& } \\
\text { acceptance, time management, } \\
\text { gauging attention span, reducing } \\
\text { distractors, organisation \& } \\
\text { planning, problem solving, } \\
\text { behaviour activation, cognitive } \\
\text { restructuring, anger control }\end{array}$ & ADHD-CSS & Self & $\begin{array}{l}\text { Yes (CBT } \\
\text { only) }\end{array}$ \\
\hline $\begin{array}{l}\text { Safren, } \\
2005 \\
\text { USA }\end{array}$ & $\mathrm{RCT}$ & $\begin{array}{l}N=31 \\
M(S D) \text { age }= \\
45.5(10.6) \\
55 \% \text { female }\end{array}$ & $\begin{array}{l}\text { Individual CBT + } \\
\text { medication }(n=16) \\
7 \text { core sessions (no } \\
\text { further information } \\
\text { provided) }\end{array}$ & $\begin{array}{l}\text { Waitlist + } \\
\text { medication }(n=15)\end{array}$ & $\begin{array}{l}\text { Psychoeducation, organisation \& } \\
\text { planning, problem solving, coping } \\
\text { with distractibility, cognitive } \\
\text { restructuring }\end{array}$ & ADHD -RS & Independent & No \\
\hline $\begin{array}{l}\text { Stevenson, } \\
2002, \\
\text { Australia }\end{array}$ & $\mathrm{RCT}$ & $\begin{array}{l}\mathrm{N}=43 \\
\mathrm{M}(\mathrm{SD}) \text { age }= \\
35.86(9.43) \\
33 \% \text { female }\end{array}$ & $\begin{array}{l}\text { Group Cognitive } \\
\text { Remediation }(\mathrm{CRP}) \pm \\
\text { medication }(\mathrm{n}=22) \\
8 \text { weekly sessions of } 2 \\
\text { hours** }\end{array}$ & $\begin{array}{l}\text { Waitlist } \pm \\
\text { medication }(n=21)\end{array}$ & $\begin{array}{l}\text { Motivation, concentration, } \\
\text { listening, impulsivity organisation, } \\
\text { anger management, self-esteem }\end{array}$ & $\begin{array}{c}\text { ADHD } \\
\text { Checklist }\end{array}$ & Self & $\begin{array}{l}\text { Yes (CBT } \\
\text { only) }\end{array}$ \\
\hline $\begin{array}{l}\text { Virta, } \\
2010, \\
\text { Finland }\end{array}$ & $\begin{array}{l}\text { Pilot } \\
\text { RCT }\end{array}$ & $\begin{array}{l}N=20 \\
M(S D) \text { age }= \\
36.1 \text { (N.R.) } \\
65 \% \text { female }\end{array}$ & $\begin{array}{l}\text { Individual CBT } \pm \\
\text { medication }(n=10) \\
10 \text { weekly sessions of } \\
60 \text { minutes }\end{array}$ & $\begin{array}{l}\text { Waitlist } \pm \\
\text { medication }(n=10)\end{array}$ & $\begin{array}{l}\text { Goals and symptoms, attention al } \\
\text { control, motivation and initiation } \\
\text { of activities, organisation \& } \\
\text { planning, stress management \& } \\
\text { relaxation, self-esteem }\end{array}$ & ASRS & $\begin{array}{l}\text { Independent } \\
\text { \& self }\end{array}$ & No \\
\hline
\end{tabular}

* coaching provided ${ }^{* *}$ weekly telephone call provided KSADS = The Kiddie-Schedule for Affective Disorders and Schizophrenia ADHD section; ADHD-CSS = ADHD Current Symptom Scale; ADHD-RS = ADHD Rating Scale; ASRS = Adult ADHD Self-Report Scale, N.R. = not reported

Page $\mathbf{2 7}$ of $\mathbf{3 1}$ 
Table 4: Study characteristics table for studies comparing CBT \pm medication with active control \pm medication (CBT-active)

\begin{tabular}{|c|c|c|c|c|c|c|c|c|c|}
\hline \multirow{2}{*}{$\begin{array}{l}\text { First author, } \\
\text { year, } \\
\text { location }\end{array}$} & \multirow[b]{2}{*}{ Design } & \multirow[b]{2}{*}{ Participants } & \multirow[b]{2}{*}{ CBT arm } & \multirow[b]{2}{*}{ Control arm } & \multirow[b]{2}{*}{ CBT content } & \multirow[b]{2}{*}{ Control content } & \multicolumn{3}{|c|}{ Assessment } \\
\hline & & & & & & & Measure & Assessor & Follow-up? \\
\hline $\begin{array}{l}\text { Estrada, } \\
2013, \\
\text { Spain }\end{array}$ & $\begin{array}{l}\text { Pilot } \\
\text { RCT }\end{array}$ & $\begin{array}{l}\mathrm{N}=32 \\
\mathrm{M}(\mathrm{SD}) \text { age }= \\
39.5(7.5) \\
53 \% \text { female }\end{array}$ & $\begin{array}{l}\text { Group CBT }+ \\
\text { medication }(n= \\
17) \\
12 \text { weekly } \\
\text { sessions of } 2 \\
\text { hours* }\end{array}$ & $\begin{array}{l}\text { Psycho- } \\
\text { education }+ \\
\text { medication } \\
(n=15)\end{array}$ & $\begin{array}{l}\text { Psychoeducation, } \\
\text { organisation \& planning, } \\
\text { problem solving, reducing } \\
\text { distractibility, } \\
\text { environmental modification, } \\
\text { behavioural analysis, } \\
\text { cognititve restructuring, } \\
\text { procrastination }\end{array}$ & $\begin{array}{l}\text { Psychoeducation (no } \\
\text { homework or practice } \\
\text { and no treatment } \\
\text { component) }\end{array}$ & ADHD-RS & Self & No \\
\hline $\begin{array}{l}\text { Safren, } \\
2010, \\
\text { USA }\end{array}$ & $\mathrm{RCT}$ & $\begin{array}{l}\mathrm{N}=86 \\
\mathrm{M}(\mathrm{SD}) \text { age }= \\
43.16(11.29) \\
44 \% \text { female }\end{array}$ & $\begin{array}{l}\text { Individual CBT }+ \\
\text { medication }(n= \\
43 \text { ) } \\
12 \text { weekly } \\
\text { sessions of } 50 \\
\text { minutes }\end{array}$ & $\begin{array}{l}\text { Relaxation }+ \\
\text { medication } \\
(n=43)\end{array}$ & $\begin{array}{l}\text { Psychoeducation, } \\
\text { organisation \& planning, } \\
\text { problem solving, reducing } \\
\text { distractibility, cognitive } \\
\text { restructuring }\end{array}$ & $\begin{array}{l}\text { Progressive muscle } \\
\text { relaxation, } \\
\text { psychoeducation, } \\
\text { supportive } \\
\text { psychotherapy }\end{array}$ & ADHD -RS & Independent & Yes \\
\hline $\begin{array}{l}\text { Solanto, } \\
2010, \\
\text { USA }\end{array}$ & $\mathrm{RCT}$ & $\begin{array}{l}N=88 \\
M(S D) \text { age }= \\
41.69(11.84) \\
66 \% \text { female }\end{array}$ & $\begin{array}{l}\text { Group Meta- } \\
\text { cognitive therapy } \\
(\mathrm{MCT})+ \\
\text { medication ( } n= \\
45) \\
12 \text { weekly } \\
\text { sessions of } 2 \\
\text { hours }\end{array}$ & $\begin{array}{l}\text { Supportive } \\
\text { therapy }+ \\
\text { medication } \\
(n=43)\end{array}$ & $\begin{array}{l}\text { Task-management, } \\
\text { organisation, planning }\end{array}$ & $\begin{array}{l}\text { Psychoeducation, goal- } \\
\text { setting, support and } \\
\text { encouragement }\end{array}$ & AISRS & Independent & No \\
\hline
\end{tabular}

* one session with a family member

ADHD-RS = ADHD Rating Scale; AISRS = Adult ADHD Investigator Symptom Rating Scale.

Page $\mathbf{2 8}$ of $\mathbf{3 1}$ 
Figure 2: Forest Plot of comparison: CBT versus Waitlist, outcome: ADHD symptoms

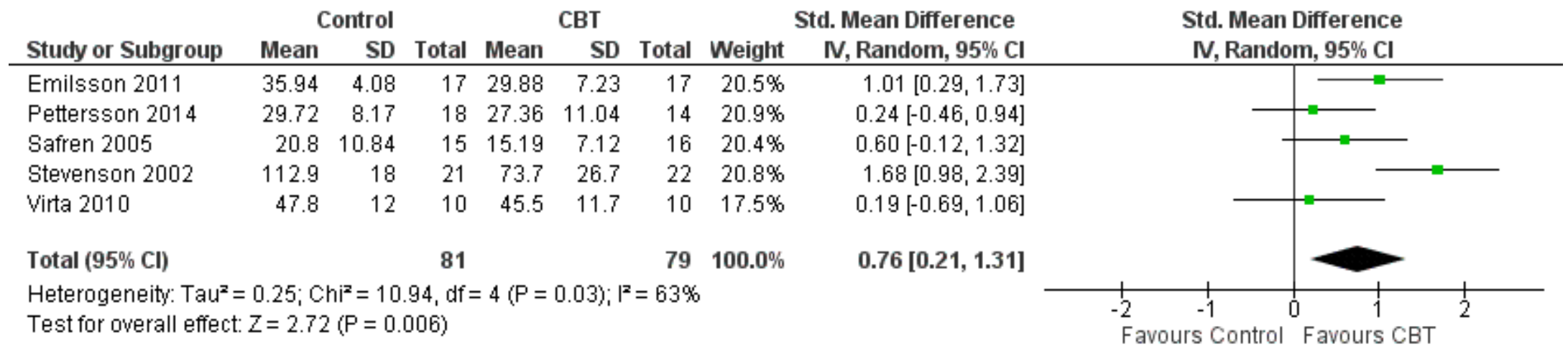


Figure 3: Forest Plot of comparison: CBT+med versus active control+med, outcome: ADHD symptoms

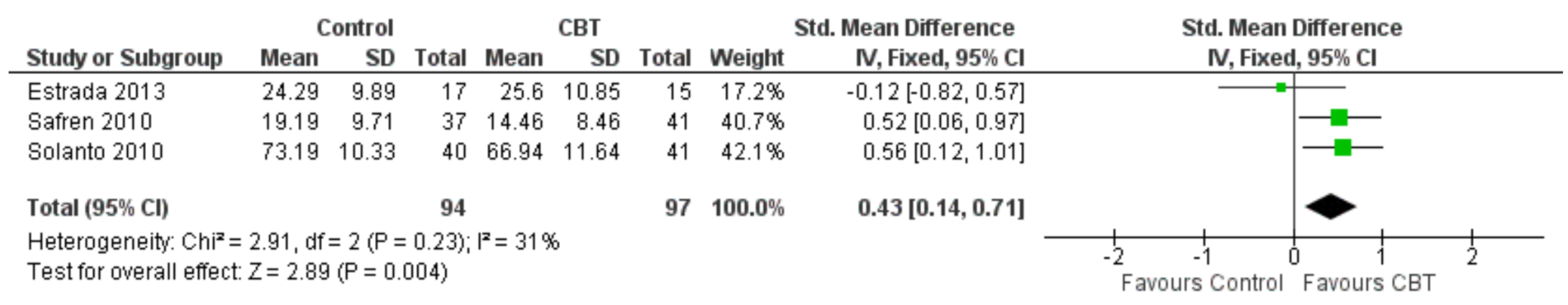


Page $\mathbf{3 1}$ of $\mathbf{3 1}$ 